\title{
No Responsibility without Discussion
}

In the seven months since its first public meeting, the British Society for Social Responsibility in Science seems to have laid the foundations for survival. It is true that the lack of money and the need to evolve a strategy still preoccupy the society, but the annual general meeting last Saturday showed that there is a hard core of dedicated supporters, many of them the younger research workers whose enthusiasm and expectation of life may be the socicty's most durable assets. There are now 625 paid-up members-six times as many as half a year ago-divided equally among physics, chemistry and biology. The membership includes 100 students and most of the rest are directly engaged in scientific research.

The society is associated with a number of local groups, not all the members of which are members of the British Society. This circumstance was one of the issues raised at the annual general meeting last weekshould the British Society for Social Responsibility in Science be a force at national level or should it concentrate on local issues? The local groups are at present largely autonomous, although the national committee of the society provides some degree of coordination and support, and, until their position has been more carefully worked out, the society will be bound to lack cohesion and weight at national level.

The activities of the British Society include working groups on science education, on attitudes to scientific projects (particularly the Apollo project), pollution and chemical and biological warfare. There have also been a number of public meetings on specific issues. Professor Maurice Wilkins and Dr R. L. Smith, respectively the president and secretary of the society, both pointed out in their opening remarks last week that the chief aims of the society are to publicize developments in science likely to have a major influence on life and the environment, to make scientists aware of the social significance of their work and to draw attention to social, political and economic pressures affecting the development of science.

The society has also elected its first National Committee to replace the ad hoc committee. Those elected were Professor S. Rose (Open University), Professor E. H. S. Burhop, Dr S. Zienau and Mr T. Norden (University College London), Dr R. L. Smith and Dr B. Drasar (St Mary's Hospital Medical School), Dr L. Sklair, Mrs H. Rose and Mr J. Rosenhead (London School of Economies), Dr S. Lal (Chelsea College), Mr M. Harvey (Westminster Hospital), Mr P. Chapman (Cambridge), and Mr D. Dickson from Medical Tribune. The president of the society is Professor M. H. F. Wilkins (King's College, London).

The development of chemical and biological weapons is a classic example of scientific research with unforeseen social consequences, and the development and use of CS was therefore a very suitable subject for the symposium which followed the annual general meeting. The symposium passed no resolutions, but the impres- sion was left that the effects of CS are not as damaging as many members of the society first believed, although everybody was convinced that CS outlines the moral and professional dilemmas of scientists engaged on military research. It was also pointed out that the development of CS shows some of the dangers that can arise when research with potentially grave social consequences is classified.

Professor Steven Rose set the scene for the symposium in a paper outlining the history of CS. He had derived most of his information from a series of papers from the Chemical Defence Experimental Establishment at Porton, which had previously been classified and which are now released for restricted circulation. The most interesting paper concerned the toxicity tests made on CS before it was released as a riot control agent. This paper is the only published material on the toxicity of the agent. After a series of tests on mice and other animals, several died after being injectcd with relatively large amounts. Moreover, no tests for chronic toxicity were reported and the evidence derived from tests on human beings was only scant. According to Professor Rose, the paper was sent to a group of distinguished scientists who duly pronounced that CS is safe for use as a riot control agent. It was suggested that the evidence which damned eyclamates was much less damning than evidence of the toxicity of CS.

Dr W. R. Jones of the Royal College of Surgeons said that his investigations of the toxicity of CS had already indicated that CS damages the kidney and liver cells of animals injected with it, and he appealed for help from other members of the society. Professor Neilands of the University of California and a team of society members who surveyed the use of CS in Ulster then gave very graphic descriptions of the effects of the agent in the field, from which it emerged that the immediate effects are not too drastic; they are confined chiefly to tightening of the chest, tears and, in some cases, smarting of the skin, nausea and diarrhoca.

Professor T. M. MacGibbon (University of Edinburgh) discusscd the legal position of CS in relation to the Geneva Protocol of 1928 on chemical and biological weapons. He considered that the protocol adequately covers the use of most chemical and biological weapons in warfare, but their use for riot control presents some rather tricky questions. Lord Ritchie-Calder, in his summing up, said that the development of CS gives rise to many problems, because it can lead to an escalation of this type of weapon if its use becomes widespread, because it is indiscriminate -it does not distinguish between combatants and noncombatants - and is a clear example of scientific research with widespread consequences. He said that, even if the symposium came to the conclusion that CS is a safe riot control agent, the British Society for Social Responsibility in Science is doing a valuable job in bringing to the attention of the public the issues involved in its development and use. 